\title{
Niacin as a drug repositioning candidate for hyperphosphatemia management in dialysis patients
}

This article was published in the following Dove Press journal:

Therapeutics and Clinical Risk Management

14 October 2014

Number of times this article has been viewed

\section{Sooyoung Shin}

Sukhyang Lee

Ajou University College of Pharmacy, Yeongtong-gu, Suwon-si, Gyeonggi-do, Korea
Correspondence: Sooyoung Shin Ajou University College of Pharmacy, 206, World cup-ro, Yeongtong-gu, Suwon-si, Gyeonggi-do 443-749, Korea $\mathrm{Tel}+82312193456$

Fax +82 31 2193435

Email syshin@ajou.ac.kr
Abstract: Nearly all patients with end-stage renal disease develop hyperphosphatemia. These patients typically require oral phosphate binders for life-long phosphorus management, in addition to dietary restrictions and maintenance dialysis. Recently, niacin, a traditional antilipemic agent, drew attention as an experimental treatment for hyperphosphatemia. The purpose of this article was to report on new findings regarding niacin's novel effects and to review the possibility of repurposing niacin for hyperphosphatemia treatment in dialysis patients by elucidating its safety and efficacy profiles along with its synergistic clinical benefits. Following approval from the Institutional Review Board, we tracked the yearly trends of order frequency of niacin in comparison with statins and sevelamer in a tertiary care hospital. Also, a Cochrane Library and PubMed literature search was performed to capture prospective clinical trials on niacin's hypophosphatemic effects in dialysis patients. Niacin use in clinical settings has been on the wane, and the major contribution to that originates from the wide use of statins. Niacin use rates have further plummeted following a trial failure which prompted the suspension of the niacin-laropiprant (a flushing blocker) combination product in the global market. Our literature search identified ten relevant articles. Overall, all studies demonstrated that niacin or nicotinamide (the metabolite form) reduced serum phosphorus levels as well as Ca-P products significantly. Additive beneficial effects on lipid parameters were also observed. Sevelamer appeared superior to niacin in a comparative study, but the study design had several limitations. The intervention dosage for niacin ranged from 375 to $1,500 \mathrm{mg}$ /day, with the average daily dose of approximately 1,000-1,500 mg. Niacin can be a patient-convenient and inexpensive alternative or adjunctive therapy for phosphorus management in dialysis patients. Further well-designed, large-scale, long-term, comparative trials are needed to successfully repurpose niacin for the new indication.

Keywords: niacin, nicotinic acid, nicotinamide, niacinamide, hyperphosphatemia, dialysis

\section{Introduction}

Abnormalities in calcium-phosphorus ( $\mathrm{Ca}-\mathrm{P})$ homeostasis and marked elevations in serum phosphorus levels are characteristic of advanced chronic renal disease. ${ }^{1}$ Nearly all patients with end-stage renal disease (ESRD) develop hyperphosphatemia, which is a significant risk factor for hypertension, vascular calcification, and substantial cardiovascular morbidity and mortality. ${ }^{2,3}$ In a study by Kestenbaum et al, ${ }^{4}$ each $1 \mathrm{mg} / \mathrm{dL}$ rise in serum phosphorus was linked to an estimated $23 \%$ increased risk of mortality. Therefore, patients with ESRD require tight control of serum phosphorus in the form of dietary restrictions in conjunction with pharmacotherapy and maintenance dialysis. ${ }^{5,6}$ Current phosphorus-lowering treatments in ESRD patients include calcium-containing phosphate binders and non-calcium containing phosphate binders, 
such as aluminum hydroxide, sevelamer, and lanthanum carbonate. Studies have shown that all phosphate binders are equally effective in lowering serum phosphorus concentrations. ${ }^{7}$ However, these agents are not comparable in their cost, toxicity, and tolerability. Therefore, the most appropriate binder must be selected in consideration of several factors, such as side effects of a particular binder as well as individual patient characteristics.

The traditional phosphate binders have common drawbacks that may negatively influence patient adherence to the medication regimen. Calcium salts have fallen out of favor due to possible hypercalcemic events and increased coronary artery and aortic valve calcification risks. ${ }^{7,8}$ All currently available phosphorus-lowering agents work by binding dietary phosphate in the gastrointestinal (GI) tract, and the chelate is eliminated in the feces, preventing the absorption of phosphorus into the bloodstream. Therefore, these agents must be taken with oral nutrient intake or tube feeding, otherwise they do not work. Other limitations include large pill burden, GI side effects, and aluminum toxicities specifically with aluminum hydroxide. ${ }^{9}$

Currently, sevelamer, an anion exchange resin, has sustained a clinically preferred safety profile over other calcium-based or non-calcium containing binders because it is not absorbed, hence poses no risk of cation-induced toxicities. ${ }^{10}$ Among the two available salt forms, the carbonate form of sevelamer is better tolerated in patients than the previous hydrochloride form, as the latter often exacerbates the tendency of patients with advanced kidney disease to metabolic acidosis. ${ }^{11}$ Also, the new powder formulation of sevelamer carbonate for oral suspension provides a novel, patient-convenient alternative to traditional tablet-form phosphate binders. However, despite the tolerability and formulational improvements, there still exist the disadvantages, such as large dose burden, GI side effects, and the strict direction to be taken three times daily with meals.

Recently, niacin, also known as nicotinic acid and vitamin B3, drew attention as an experimental option for elevated serum phosphorus concentrations in chronic renal disease patients. ${ }^{12-15}$ Animal models suggested that niacin decreases phosphorus absorption in the GI tract by the direct inhibitory effect of nicotinamide (or niacinamide), a metabolite of niacin, on active sodium-phosphate cotransporter in the small intestine. ${ }^{16,17}$ This is a distinct mechanism of action from the traditional phosphate binders. Preliminary studies showed that niacin can be a useful primary or add-on therapy for hyperphosphatemia in ESRD patients. ${ }^{12-15}$ Once-daily oral niacin treatment for elevated serum phosphorus levels has been investigated in a limited number of clinical trials in dialysis patients, ${ }^{18}$ but the clinical investigation of niacin's novel effects is still in its early stages.

As the first cholesterol-reducing agent, niacin has welldocumented beneficial effects in hyperlipidemia management. It specifically reduces serum triglycerides as well as low-density lipoprotein cholesterol (LDL-C) and most effectively raises high-density lipoprotein cholesterol (HDL-C), by up to $35 \% .{ }^{19}$ Boosting HDL-C levels can be as important as lowering LDL-C because studies have confirmed the status of low HDL-C level as an independent risk factor for cardiovascular events. ${ }^{20,21}$ Despite the robust evidence for the impact of niacin treatment for dyslipidemia, present-day researchers encounter practical challenges when organizing clinical trials to investigate niacin's novel effects - the vitamin is now rarely used in clinical settings.

With its cost-effectiveness and additive effects as a traditional dyslipidemia treatment, niacin can be a promising candidate for drug repositioning as a phosphorus-lowering agent in ESRD patients. However, due to a paucity of concrete clinical evidence on its efficacy and safety in comparison with the gold standard phosphorus-lowering therapy, clinicians are still faced with uncertainties in practice as to whether they should consider niacin as a primary or adjunctive hyperphosphatemia treatment in ESRD patients. The purpose of this article was to report on new findings regarding the use of niacin in the treatment of hyperphosphatemia in dialysis patients and to review the possibility of repurposing niacin for the new indication by elucidating its safety and efficacy profiles along with its synergistic clinical benefits.

\section{Methods}

After obtaining approval from the Institutional Review Board in June 2014, we tracked the yearly trends of order frequency of niacin in comparison with statins and sevelamer since the adoption of electronic medical records in 1999 at the Ajou University Hospital in Korea.

We also performed a literature search to identify clinical trials of ESRD patients on dialysis that evaluated the effects of niacin and its analog in lowering serum phosphorus concentrations. PubMed and Cochrane Library were searched, without language and geographical restrictions, for articles published since 2004. The search terms included niacin, nicotinic acid, nicotinamide, niacinamide, and hyperphosphatemia. The reference lists of captured articles and previous reviews were also searched to find additional primary 
literature that may not have been captured through the initial search. Two reviewers independently screened the article titles, abstracts, and full texts to identify clinical trials that may be suitable for inclusion criteria. The inclusion criteria were broken into four categories: 1) only prospective studies, including placebo- or comparator-controlled trials, were eligible; 2) adult patients on hemodialysis or peritoneal dialysis were included; 3 ) niacin (nicotinic acid) or nicotinamide (niacinamide) must have been used for hyperphosphatemia treatment; and 4) endpoints must include serum phosphorus levels, and other outcome measures include corrected/uncorrected serum $\mathrm{Ca}$, Ca-P product, HDL-C, LDL-C, triglycerides, thrombocytopenia, diarrhea, flushing, pruritus, and rash. We also conducted another search through http://clinicaltrials.gov to identify ongoing clinical trials. A dose-finding study (NCT01200784) was returned through this search, but the results have not yet been published.

\section{Results}

\section{Niacin use on the wane}

The major contribution to the usage drop originates from the rise of statins, which include the blockbuster cholesterollowering medications, such as atorvastatin and rosuvastatin. As an example, the yearly trends of order frequency of niacin versus statins in a tertiary-care hospital with over 1,000 patient-beds in Korea are presented in Figure 1. Niacin use rates were constantly minimal and have plummeted into near nonexistence since 2012. Conversely, statin use rates, especially atorvastatin and rosuvastatin, have skyrocketed over the past 15 years. Additionally, Figure 2 demonstrates the yearly order patterns of niacin versus sevelamer, the phosphate binder with the most favorable safety profile. The current order patterns clearly show that designing a comparative study between niacin and sevelamer retrospectively is not plausible.

Another factor that might have negatively affected the usage rates of niacin is its most prominent side effect, facial flushing. Niacin promotes cutaneous vasodilation via stimulating the production of prostaglandins. ${ }^{22}$ The subsequent burning sensation is harmless but unpleasant and made it difficult for patients to comply with niacin therapy. Pretreatment with aspirin has been frequently utilized to reduce the incidence of flushing, but provided limited effects. In 2007, Merck developed a new version of niacin (Tredaptive) that was combined with laropiprant, a novel and highly selective prostaglandin D2 receptor subtype 1 inhibitor, to decrease the incidence and intensity of niacin-induced skin flushing. ${ }^{23}$ However, unexpected adverse effects, such as bleeding and infections, have been reported with the combined niacin-laropiprant product, ${ }^{23}$ and no concrete evidence has been provided on which component of the combination is responsible for the adverse outcomes. The study results prompted the suspension of Tredaptive worldwide and, since then, the use of niacin has further plummeted. All these factors are posing practical barriers to implementing further clinical investigation on niacin.

\section{Previous study results on niacin's hypophosphatemic effects}

By our literature search, 12 relevant articles were originally identified, and two were excluded as they only included patients free of clinical renal disease. The ten eligible trials enrolled 261 adult patients in the active group and 135 adult patients in the control group. Of the ten articles, five were

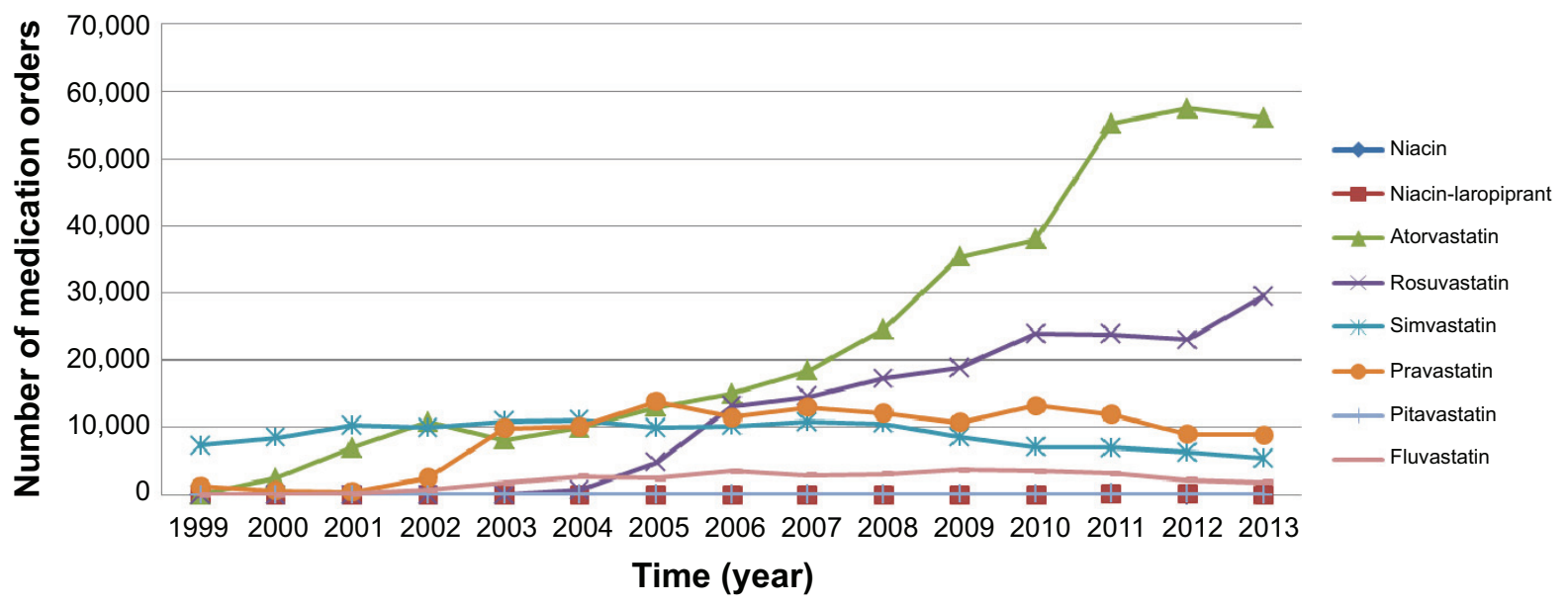

Figure I Order frequency of niacin versus statins in a single tertiary-care institution.

Note: The number of medical orders for niacin, niacin-laropiprant, and pitavastatin are near zero. 


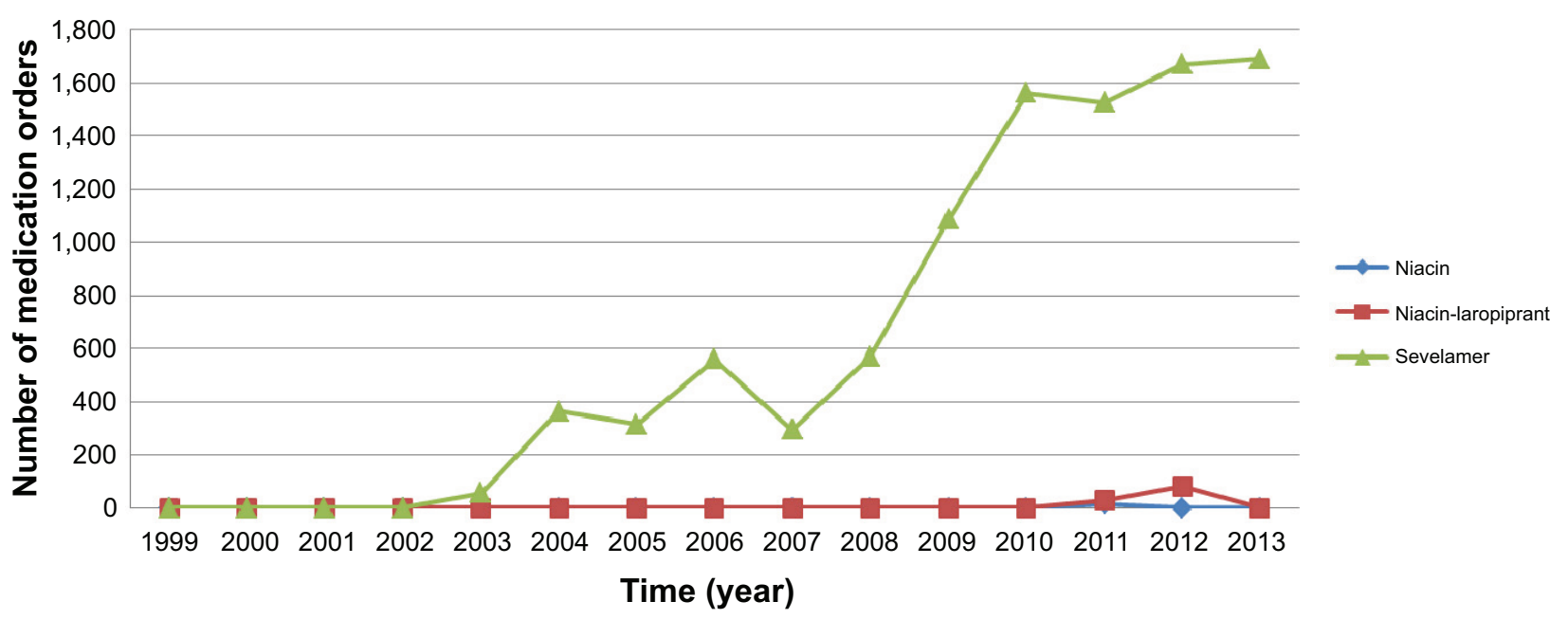

Figure $\mathbf{2}$ Order frequency of niacin versus sevelamer in a single tertiary-care institution.

a placebo-controlled design including two crossover trials, and one was a head-to-head comparison against sevelamer hydrochloride. The important findings from the selected trials are summarized in Table 1, including concomitant statin use and changes in lipid parameters. Niacin was the study drug in six trials; while in four trials, the metabolite form of nicotinamide (or niacinamide) was studied. Other phosphate binder use was not strictly limited in five studies. Statin was used concomitantly in three trials, while the remaining trials did not specify the information. ${ }^{12-15,18,24-28}$

A prospective, open-label study of 2004 in Japan enrolled 65 hemodialysis patients with elevated baseline phosphorus. ${ }^{12}$ The patients received nicotinamide for 12 weeks, at a starting dose of $500 \mathrm{mg}$ /day, with titration every 2 weeks by $250 \mathrm{mg} /$ day. The serum phosphorus level decreased from $6.9 \pm 1.5$ to $5.4 \pm 1.3 \mathrm{mg} / \mathrm{dL}(P<0.0001)$, and the $\mathrm{Ca}-\mathrm{P}$ product dropped significantly from $59.8 \pm 14.5$ to $47.3 \pm 13.4 \mathrm{mg}^{2} / \mathrm{dL}^{2}$ during the 12 -week treatment $(P<0.0001)$. Adverse effects of nicotinamide included reversible thrombocytopenia and diarrhea.

Another prospective, open-label study in India enrolled 34 patients on maintenance hemodialysis with hyperphosphatemia. ${ }^{13}$ Niacin therapy was initiated at $375 \mathrm{mg} /$ day, with dose increase to twice daily if necessary after 2 weeks of therapy. Following the 8 weeks of treatment, the serum phosphorus level decreased from $7.7 \pm 1.5$ to $5.6 \pm 1 \mathrm{mg} / \mathrm{dL}(P<0.001)$, and a concurrent fall in $\mathrm{Ca}-\mathrm{P}$ product was observed from $63.1 \pm 15.1$ to $48.7 \pm 10.9 \mathrm{mg}^{2} / \mathrm{dL}^{2}(P<0.001)$. Two patients experienced mild pruritus, otherwise niacin was well tolerated.

In a German study of 2007, researchers enrolled 17 dialysis patients who tolerated a daily dose of at least $1,000 \mathrm{mg}$ (average dosage 1,470 $\pm 110 \mathrm{mg} /$ day).${ }^{14} \mathrm{Niacin}$ was initiated at $375 \mathrm{mg} /$ day, with titration every 2 weeks to $500,1,000,1,500$, and 2,000 mg/day, respectively. Six patients stopped therapy prematurely because of flushing, weight loss, or hypotension during dialysis. Overall, serum phosphorus values decreased from $7.2 \pm 0.5$ to $5.9 \pm 0.6 \mathrm{mg} / \mathrm{dL}(P=0.015)$. Adverse effects due to niacin were flushing and diarrhea.

A Colombian study of 2008 recruited nine renal disease patients on dialysis with a baseline serum phosphorus level $>5.5 \mathrm{mg} / \mathrm{dL}$ despite standard phosphate binder treatment. ${ }^{15}$ Patients were started on niacin $500 \mathrm{mg} /$ day, and 3 months later, the dosage was increased to $1,000 \mathrm{mg} /$ day. The 8-month treatment resulted in a significant reduction in serum phosphorus from $6.46 \pm 0.53$ to $3.94 \pm 0.76 \mathrm{mg} / \mathrm{dL}$ $(P<0.01)$. The reduction in $\mathrm{Ca}-\mathrm{P}$ product was also significant. No adverse events attributable to niacin were reported.

Cheng et $\mathrm{al}^{24}$ enrolled 33 hemodialysis patients with elevated baseline phosphorus in a crossover trial of nicotinamide versus placebo. The patients were randomly assigned to 8 weeks of active or placebo treatment. Nicotinamide was started at $500 \mathrm{mg} /$ day, then the dosage was titrated up to $1,000 \mathrm{mg} /$ day at week 3 and $1,500 \mathrm{mg}$ /day at week 5 . A 2-week washout period preceded the switch from treatment to placebo or vice versa. A significant fall in serum phosphorus was achieved, from $6.26 \pm 1.28$ to $5.47 \pm 1.49 \mathrm{mg} / \mathrm{dL}$ with nicotinamide $(P=0.02)$, but not with placebo. The Ca-P product also fell significantly with nicotinamide. One patient experienced diarrhea and another complained of a transient rash while receiving nicotinamide. Thrombocytopenia developed in nine patients on nicotinamide and five on placebo.

Young et $\mathrm{al}^{25}$ conducted an 8 -week, randomized, placebo-controlled trial of 15 peritoneal dialysis patients 
with a baseline phosphorus value $>4.9 \mathrm{mg} / \mathrm{dL}$. Patients were initiated on nicotinamide $500 \mathrm{mg} /$ day, with titration to $1,500 \mathrm{mg}$ /day. In the active group, the plasma phosphorus fell by an average of $0.7 \pm 0.9 \mathrm{mg} / \mathrm{dL}$, and the absolute between-group difference in serum phosphorus levels was $1.1 \mathrm{mg} / \mathrm{dL}(P=0.037)$. Two patients in the active arm had to discontinue treatment due to drug-induced adverse effects, such as diarrhea and pruritus.

In an Iranian study by Shahbazian et al, ${ }^{26} 48$ dialysis patients with hyperphosphatemia were enrolled in an 8-week, randomized, placebo-controlled trial. The initial dose of nicotinamide was $500 \mathrm{mg} /$ day in the first 4 weeks, then the dosage was titrated up to $1,000 \mathrm{mg} /$ day in the remaining 4 weeks. The nicotinamide treatment achieved a significant fall in serum phosphorus levels, from $5.9 \pm 0.58 \mathrm{mg} / \mathrm{dL}$ to $4.77 \pm 1.43 \mathrm{mg} / \mathrm{dL}$ at week $4(P=0.002)$ and to $4.66 \pm 1.06 \mathrm{mg} / \mathrm{dL}$ at week $8(P=0.000)$. The mean Ca-P product also decreased significantly. Adverse effects related to nicotinamide included thrombocytopenia and diarrhea.

More recently, Aramwit et $\mathrm{al}^{18}$ in Thailand reported the results from a 12-week, randomized, placebo-controlled trial of 28 hemodialysis patients with hyperphosphatemia. The initial niacin dose was $375 \mathrm{mg} /$ day, with titration once weekly to 500,750 , and $1,000 \mathrm{mg} /$ day, as tolerated. The average serum phosphorus of the active group decreased significantly from $7.13 \pm 1.09 \mathrm{mg} / \mathrm{dL}$ to $5.65 \pm 1.22 \mathrm{mg} / \mathrm{dL}$ $(P<0.001)$. However, the between-group difference in the post-intervention serum phosphorus levels was not significant. The level of Ca-P product dropped significantly in the treatment group $(P<0.001)$. One patient experienced niacininduced hot flushes.

In a crossover study by Edalat-Nejad et $\mathrm{al}^{27} 37$ hemodialysis patients with hyperphosphatemia were randomly assigned to placebo or niacin with titration every 2 weeks from 400 to 600,800 , and 1,000 mg/day, respectively. After a washout period of 2 weeks, the patients were placed on the alternative therapy for the next 8 weeks. During the 8 -week niacin treatment, serum phosphorus decreased from $6.66 \pm 1.40$ to $5.96 \pm 0.87 \mathrm{mg} / \mathrm{dL}(P=0.006)$. Common adverse effects related to niacin included flushing, GI symptoms, and mild pruritus.

Lastly, Ahmadi et $\mathrm{al}^{28}$ in Iran conducted the first headto-head comparative study of niacin against sevelamer hydrochloride in 40 hemodialysis patients with hyperphosphatemia. Flat doses of $500 \mathrm{mg} /$ day for niacin versus $1,600 \mathrm{mg} /$ day for sevelamer were used during the 4-week study period. Both groups demonstrated a significant drop in serum phosphorus $(2.2 \pm 0.6 \mathrm{mg} / \mathrm{dL}, P<0.0001$ and $1.7 \pm 1 \mathrm{mg} / \mathrm{dL}, P=0.004$, respectively). Reduction in the $\mathrm{Ca}-\mathrm{P}$ product in the sevelamer group was 21.6 $\pm 7(P<0.0001)$, while that of the niacin group was $16.3 \pm 11(P=0.007)$. Sevelamer appeared superior to niacin in this short-term study.

\section{Discussion}

As niacin's clinical use has been traditionally limited to dyslipidemia treatment, institutional electronic medical records mostly lack baseline and repeated phosphorus measures which are essential to examine the vitamin's potential effects on serum phosphorus as well as Ca-P products. The paucity of relevant data in addition to Merck's 2013 decision to withdraw the niacin-laropiprant product from the global market made it difficult for researchers to initiate further clinical investigation on niacin's novel effects. Subsequently, the combination product failure also overshadowed the drug repositioning prospects of niacin in the treatment of hyperhosphatemia in ESRD patients. Under these circumstances, it is deemed important and timely to provide for the clinical world an updated, comprehensive review of new research findings regarding niacin's hypophosphatemic effects and provide suggestions for future studies.

Preliminary clinical trials demonstrated that niacin has the potential to be used as a cost-effective, alternative or adjunctive phosphorus-lowering treatment in dialysis patients. ${ }^{12-15}$ The availability of numerous generic formulations makes it more attractive to patients because they would prefer an inexpensive treatment option as a life-long therapy over patented phosphate binders such as sevelamer carbonate. In addition, with its well-documented, additive effects on lipid profile, chronic renal disease patients particularly with cardiovascular comorbidities can expect synergistic cardioprotective benefits from niacin therapy. ${ }^{29-31}$ Other advantages include its flexible once- or twice-daily dosing regimen as opposed to the dosing schedule of traditional phosphate binders typically given three times daily with meals. This will significantly improve patient convenience as well as compliance with therapy while decreasing daily pill burden.

Finding ways to overcome side effects contributable to niacin is a prerequisite for successfully identifying and developing the new indication for the vitamin. Niacininduced facial flushing is rarely severe enough to lead patients to discontinue therapy, but it is the major cause of patient discomfort. Initiation at a low dose with slow titration and pretreatment with aspirin can attenuate the incidence and severity of the cutaneous side effect. ${ }^{32}$ Additionally, selecting the extended-release (ER) formulation can help. Niacin is metabolized in the liver by either a conjugation 
Table I Summary of the selected clinical trials of niacin and nicotinamide in end-stage renal disease patients on dialysis

\begin{tabular}{|c|c|c|c|c|c|c|c|c|}
\hline Trial & $\begin{array}{l}\text { Active } \\
\text { (A) group }\end{array}$ & $\begin{array}{l}\text { Control } \\
\text { (C) group }\end{array}$ & $\begin{array}{l}\text { No of } \\
\text { patients } \\
\text { (A/C), n }\end{array}$ & $\begin{array}{l}\text { Treatment } \\
\text { duration }\end{array}$ & $\begin{array}{l}\text { Baseline } \\
\text { serum } \mathbf{P} \text {, } \\
\mathrm{mg} / \mathrm{dL}\end{array}$ & $\begin{array}{l}\text { Mean } \\
\text { age, years }\end{array}$ & $\begin{array}{l}\text { Mean duration } \\
\text { of dialysis }\end{array}$ & $\begin{array}{l}\text { Treatment } \\
\text { intervention with } \\
\text { dose titration, } \\
\text { mg/day }\end{array}$ \\
\hline 12 & Nicotinamide & None & $65 / 0$ & 12 weeks & $>6.0$ & $57.0 \pm 11.5$ & $\begin{array}{l}6.5 \pm 5.2 \text { years, } \\
3 \text { times weekly }\end{array}$ & $\begin{array}{l}500, \text { increased by } \\
250 \text { every } 2 \text { weeks }\end{array}$ \\
\hline 13 & Niacin ER & None & $34 / 0$ & 8 weeks & $>6.0$ & $48 \pm 13$ & $\begin{array}{l}8.7 \pm 9.6 \text { months, } \\
2 \text { times weekly }\end{array}$ & $\begin{array}{l}375 \text {, increased to } \\
\text { twice daily after } \\
2 \text { weeks }\end{array}$ \\
\hline 14 & Niacin ER & None & $17 / 0$ & 12 weeks & $5.7 \pm 0.4$ & $65.4 \pm 10.2$ & $3.8 \pm 2.1$ years & $\begin{array}{l}375 \text {, increased to } \\
500,1,000,1,500 \text {, and } \\
2,000 \text { every } 2 \text { weeks }\end{array}$ \\
\hline 15 & Niacin ER & None & $9 / 0$ & 8 months & $>5.5$ & 48.2 & 34.7 months & $\begin{array}{l}500 \text {, increased to } \\
1,000 \text { after } 3 \text { months }\end{array}$ \\
\hline 24 & Nicotinamide & $\begin{array}{l}\text { Placebo } \\
\text { crossover }\end{array}$ & $33 / 33$ & 20 weeks & $>5.0$ & 52.6 & 4.4 years & $\begin{array}{l}500, \text { increased to } \\
I, 000 \text { and } I, 500 \\
\text { every } 2 \text { weeks }\end{array}$ \\
\hline 25 & Nicotinamide & Placebo & $8 / 7$ & 8 weeks & $>4.9$ & $53.4 \pm 10.9$ & $|8 \pm 1|$ months & $\begin{array}{l}500 \text {, increased to } \\
1,000 \text { and } I, 500 \\
\text { every } 2 \text { weeks }\end{array}$ \\
\hline 26 & Nicotinamide & Placebo & $24 / 24$ & 8 weeks & $\geq 5$ & $\begin{array}{l}\text { A group: } \\
53.9 \pm 11.1 \\
\text { C group: } \\
54.1 \pm 16.6\end{array}$ & $\begin{array}{l}\text { A group: } \\
40 \pm 37 \text { months } \\
\text { C group: } \\
37 \pm 28 \text { months }\end{array}$ & $\begin{array}{l}500, \text { increased to } \\
\mathrm{I}, 000 \text { after } 4 \text { weeks }\end{array}$ \\
\hline 18 & Niacin ER & Placebo & $14 / 14$ & 12 weeks & $>5.5$ & $\begin{array}{l}\text { A group: } \\
45.5 \pm 11.5 \\
\text { C group: } \\
49.4 \pm 10.9\end{array}$ & $\begin{array}{l}\text { A group: } \\
9.3 \pm 3.9 \text { years } \\
\text { C group: } \\
9.6 \pm 4.7 \text { years }\end{array}$ & $\begin{array}{l}375, \text { increased } \\
\text { to } 500,750 \text {, and } \\
\text { I,000 weekly }\end{array}$ \\
\hline 27 & Niacin ER & $\begin{array}{l}\text { Placebo } \\
\text { crossover }\end{array}$ & $37 / 37$ & 8 weeks & $5-7$ & $57 \pm 11$ & NR & $\begin{array}{l}400, \text { increased } \\
\text { to } 600,800, \text { and } \\
1,000 \text { every } 2 \text { weeks }\end{array}$ \\
\hline 28 & Niacin ER & $\begin{array}{l}\text { Sevelamer } \\
\mathrm{HCl}\end{array}$ & $20 / 20$ & 4 weeks & $>6$ & $\begin{array}{l}\text { A group: } \\
51 \pm 16.1 \\
\text { C group: } \\
48.5 \pm 15.5\end{array}$ & $\begin{array}{l}\text { A group: } \\
6.0 \pm 4.4 \\
\text { years } \\
\text { C group: } 5.6 \pm 5.3 \\
\text { years }\end{array}$ & 500 \\
\hline
\end{tabular}

Notes: $\uparrow$, increased; $\downarrow$, decreased.

Abbreviations: D, diarrhea; F, flushing; HDL, high-density lipoprotein; LDL, low-density lipoprotein; NR, not reported; NS, not significant; Pr, pruritus; R, rash; ER, extended release; $\mathrm{HCl}$, hydrochloride; GI, gastrointestinal; Ca-P, calcium-phosphorus; T, thrombocytopenia; TG, triglycerides.

or amidation pathway. The metabolite produced via the amidation pathway, nicotinamide, is mainly associated with GI symptoms and hepatotoxicity. Amidation is categorized as a high-affinity and low-capacity pathway. ${ }^{22}$ Therefore, if niacin exists in low concentrations over time, such as with a sustained release formulation, amidation becomes a predominant metabolic pathway and produces more nicotinamide as a result..$^{33}$ In contrast, immediate-release niacin is likely to quickly saturate the low-capacity amidation pathway, shifting hepatic metabolism to conjugation. This will lead to greater production of nicotinuric acid and subsequent prostaglandin, resulting in more episodes of flushing. With its moderately slow metabolic rate, the ER formulation appears to be associated with the least incidence of flushing, GI symptoms, and hepatotoxicity. ${ }^{22}$

Despite promising results from previous trials worldwide, niacin's efficacy and safety data compared with the gold standard phosphate binder is very limited, and its clinical dosage has not yet been clearly defined. The only headto-head trial thus far is the 2012 study by Ahmadi et al. ${ }^{28}$ The research had several limitations in terms of sample size, subtherapeutic dose with no titration, treatment duration, 


\begin{tabular}{|c|c|c|c|c|c|c|}
\hline $\begin{array}{l}\text { Other phosphate } \\
\text { binder use }\end{array}$ & $\begin{array}{l}\text { Mean P decrease, } \\
\mathrm{mg} / \mathrm{dL}\end{array}$ & $\begin{array}{l}\text { Mean Ca change, } \\
\mathrm{mg} / \mathrm{dL}\end{array}$ & $\begin{array}{l}\text { Ca-P product } \\
\text { decrease, } \mathrm{mg}^{2} / \mathrm{dL}^{2}\end{array}$ & $\begin{array}{l}\text { Adverse } \\
\text { events, } n\end{array}$ & $\begin{array}{l}\text { Statin } \\
\text { use, \% }\end{array}$ & $\begin{array}{l}\text { Lipid } \\
\text { parameters }\end{array}$ \\
\hline No & $1.5(P<0.000 \mathrm{I})$ & NS & $\begin{array}{l}12.5 \\
(P<0.0001)\end{array}$ & $\begin{array}{l}\mathrm{D}: 5 \\
\mathrm{~T}: \mathrm{I}\end{array}$ & NR & $\begin{array}{l}\text { HDL: } \uparrow \\
\text { LDL: } \downarrow \\
\text { TG: NS }\end{array}$ \\
\hline No & $2.1(P<0.00 I)$ & $\begin{array}{l}\text { Increased by } 0.4 \\
(P<0.015)\end{array}$ & $\begin{array}{l}\mid 4.4 \\
(P<0.00 \mid)\end{array}$ & Mild Pr: 2 & NR & NR \\
\hline No & $1.3(P=0.015)$ & NS & NR & $\begin{array}{l}\text { F: } 7 \\
\text { D: I }\end{array}$ & 65 & $\begin{array}{l}\text { HDL: } \uparrow \\
\text { LDL: NS } \\
\text { TG: NS }\end{array}$ \\
\hline No & $2.52(P<0.01)$ & $\begin{array}{l}\text { Increased by } 0.62 \\
(P<0.05)\end{array}$ & $\sim 20$ & $\begin{array}{l}\text { None } \\
\text { observed }\end{array}$ & $N R$ & $\begin{array}{l}\text { HDL: } \uparrow \\
\text { LDL: NS } \\
\text { TG: } \downarrow\end{array}$ \\
\hline Yes & $0.79(P=0.02)$ & NS & $\begin{array}{l}7 \\
(P=0.02)\end{array}$ & $\begin{array}{l}\text { T: } 9 \\
\text { D: I } \\
\text { R: I }\end{array}$ & NR & $\begin{array}{l}\text { HDL: } \uparrow \\
\text { LDL: NS } \\
\text { TG: NS }\end{array}$ \\
\hline Yes & $\begin{array}{l}0.7 \pm 0.9, \text { between-group } \\
\text { difference } I . I(P=0.037)\end{array}$ & Increased by 0.3 & Unchanged & $\begin{array}{l}\mathrm{D}: \mathrm{I} \\
\mathrm{R}: \mathrm{I}\end{array}$ & 75 & $\begin{array}{l}\text { HDL: NS } \\
\text { LDL: NS } \\
\text { TG: NS }\end{array}$ \\
\hline Yes & $\begin{array}{l}4 \text { weeks: } \\
\text { I. } 13(P=0.002) \\
8 \text { weeks: } \\
\text { I. } 24 \\
(P=0.000)\end{array}$ & NS & $\begin{array}{l}4 \text { weeks: } \\
9.5(P=0.004) \\
8 \text { weeks: } \\
\text { I0.49 } \\
(P=0.002)\end{array}$ & $\begin{array}{l}\text { T: } 10 \\
\text { D: } 4\end{array}$ & NR & $\begin{array}{l}\text { HDL: } \uparrow \\
\text { LDL: } \downarrow \\
\text { TG: NS }\end{array}$ \\
\hline Yes & $\begin{array}{l}\text { I.48 } \\
(P<0.00 \text { I), between-group } \\
\text { difference NS }\end{array}$ & NS & $\begin{array}{l}\sim 13 \\
(P<0.001)\end{array}$ & F: I & 50 & HDL: $\uparrow$ \\
\hline Yes & $0.7(P=0.006)$ & NS & NR & $\begin{array}{l}\text { F: } 3 \\
\text { Gl: } 2 \\
\text { Mild Pr: } 7\end{array}$ & NR & $\begin{array}{l}\text { HDL: } \uparrow \\
\text { LDL: NS } \\
\text { TG: NS }\end{array}$ \\
\hline No & 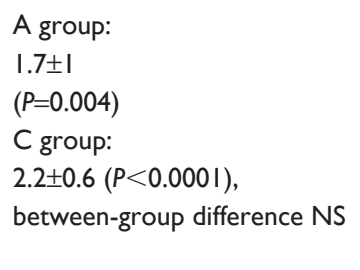 & NS & $\begin{array}{l}\text { A group: } \\
|6.3 \pm| \mid \\
(P=0.007) \\
\text { C group: } \\
21.6 \pm 7(P<0.000 \mid) \\
\text { between-group } \\
\text { difference NS }\end{array}$ & F: 5 & NR & $\begin{array}{l}\text { HDL: NS } \\
\text { LDL: NS } \\
\text { TG: } \downarrow\end{array}$ \\
\hline
\end{tabular}

comparator salt form, and confounder control. A dose-finding study (NCT01200784) in over 250 hemodialysis patients has been completed in July 2011, but the results remain unpublished. As a result, the optimal dosing strategy for niacin remains uncertain.

Further large-scale, randomized-controlled, comparative trials are required to clarify the uncertainties faced by providers in clinical practice regarding the use of niacin as monotherapy or add-on therapy for hyperphosphatemia in dialysis patients. Following are suggestions for future studies. As it is unclear whether nicotinamide has equivalent effects on lipid parameters, niacin is recommended to be chosen as a study drug to ensure the synergistic antilipemic effects. Based on previous studies, the intervention dosage ranged from 375 to $1,500 \mathrm{mg} /$ day, with the average daily dose of approximately 1,000 to $1,500 \mathrm{mg}$. The usual dose of niacin ER for dyslipidemia control, 1,000-2,000 g/day, is similar to the estimated dose for hyperphosphatemia treatment. Researchers, therefore, may start low and titrate up the niacin dosage to the goal daily dose of approximately 1,000-1,500 mg. Recruiting patients with a higher phosphorus level at baseline may help researchers to readily identify the significance of hypophosphatemic 
effects of interventions. ${ }^{34}$ To evaluate the sustainability of niacin's therapeutic effects, long-term follow-up of patients is recommended. Lastly, potential confounders, such as dietary phosphorus intake, other phosphate binder use, and concurrent statin therapy, are required to be adequately controlled.

\section{Conclusion}

Niacin can be a patient-convenient and inexpensive alternative or add-on therapy for phosphorus management in dialysis patients. With its additive antilipemic effects, it can also provide synergistic benefits for chronic renal disease patients with cardiovascular comorbidities. Further well-designed, large-scale, long-term, comparative trials are needed to successfully repurpose niacin for the new indication.

\section{Acknowledgments}

This study was supported by the new faculty research fund of Ajou University and the Bio and Medical Technology Development Program of the National Research Foundation funded by the Ministry of Science, Information and Communications Technology, and Future Planning, Republic of Korea (No. 2013M3A9B5075838).

\section{Disclosure}

The authors declare that there is no conflict of interests regarding the publication of this article.

\section{References}

1. Tonelli M, Pannu N, Manns B. Oral phosphate binders in patients with kidney failure. $N$ Engl J Med. 2010;362(14):1312-1324.

2. Friedman EA. Consequences and management of hyperphosphatemia in patients with renal insufficiency. Kidney Int Suppl. 2005;(95):S1-S7.

3. Lopes AA, Tong L, Thumma J, et al. Phosphate binder use and mortality among hemodialysis patients in the Dialysis Outcomes and Practice Patterns Study (DOPPS): evaluation of possible confounding by nutritional status. Am J Kidney Dis. 2012;60(1):90-101.

4. Kestenbaum B, Sampson JN, Rudser KD, et al. Serum phosphate levels and mortality risk among people with chronic kidney disease. J Am Soc Nephrol. 2005;16(2):520-528.

5. KDIGO clinical practice guideline for the diagnosis, evaluation, prevention, and treatment of chronic kidney disease-mineral and bone disorder (CKD-MBD). Kidney Int Suppl. 2009;(113):S1-S130.

6. Hruska KA, Mathew S, Lund R, Qiu P, Pratt R. Hyperphosphatemia of chronic kidney disease. Kidney Int. 2008;74(2):148-157.

7. Liu L, Wang Y, Chen H, Zhu X, Zhou L, Yang Y. The effects of noncalcium-based phosphate binders versus calcium-based phosphate binders on cardiovascular calcification and bone remodeling among dialysis patients: a meta-analysis of randomized trials. Ren Fail. 2014:1-9.

8. Goodman WG. Vascular calcification in chronic renal failure. Lancet. 2001;358(9288):1115-1116.

9. Malluche HH. Aluminium and bone disease in chronic renal failure. Nephrol Dial Transplant. 2002;17 Suppl 2:21-24.

10. Chertow GM, Burke SK, Raggi P; Treat to Goal Working Group. Sevelamer attenuates the progression of coronary and aortic calcification in hemodialysis patients. Kidney Int. 2002;62(1):245-252.
11. Oka Y, Miyazaki M, Matsuda H, et al. Sevelamer hydrochloride dosedependent increase in prevalence of severe acidosis in hemodialysis patients: analysis of nationwide statistical survey in Japan. Ther Apher Dial. 2014;18(1):37-43.

12. Takahashi Y, Tanaka A, Nakamura T, et al. Nicotinamide suppresses hyperphosphatemia in hemodialysis patients. Kidney Int. 2004;65(3): 1099-1104.

13. Sampathkumar K, Selvam M, Sooraj YS, Gowthaman S, Ajeshkumar RN. Extended release nicotinic acid - a novel oral agent for phosphate control. Int Urol Nephrol. 2006;38(1):171-174.

14. Muller D, Mehling H, Otto B, et al. Niacin lowers serum phosphate and increases HDL cholesterol in dialysis patients. Clin J Am Soc Nephrol. 2007;2(6):1249-1254.

15. Restrepo Valencia CA, Cruz J. [Safety and effectiveness of nicotinic acid in the management of patients with chronic renal disease and hyperlipidemia associated to hyperphosphatemia]. Nefrologia. 2008;28(1):61-66. Spanish.

16. Katai K, Tanaka H, Tatsumi S, et al. Nicotinamide inhibits sodiumdependent phosphate cotransport activity in rat small intestine. Nephrol Dial Transplant. 1999;14(5):1195-1201.

17. Eto N, Miyata Y, Ohno H, Yamashita T. Nicotinamide prevents the development of hyperphosphataemia by suppressing intestinal sodiumdependent phosphate transporter in rats with adenine-induced renal failure. Nephrol Dial Transplant. 2005;20(7):1378-1384.

18. Aramwit P, Srisawadwong R, Supasyndh O. Effectiveness and safety of extended-release nicotinic acid for reducing serum phosphorus in hemodialysis patients. $J$ Nephrol. 2012;25(3):354-362.

19. Toth PP. High-density lipoprotein and cardiovascular risk. Circulation. 2004;109(15):1809-1812.

20. Yusuf S, Hawken S, Ounpuu S, et al. Effect of potentially modifiable risk factors associated with myocardial infarction in 52 countries (the INTERHEART study): case-control study. Lancet. 2004;364(9438): 937-952.

21. Barter P, Gotto AM, LaRosa JC, et al. HDL cholesterol, very low levels of LDL cholesterol, and cardiovascular events. N Engl J Med. 2007; 357(13):1301-1310.

22. Pieper JA. Overview of niacin formulations: differences in pharmacokinetics, efficacy, and safety. Am J Health Syst Pharm. 2003;60(13 Suppl 2):S9-S14; quiz S25.

23. Group HTC, Landray MJ, Haynes R, et al. Effects of extendedrelease niacin with laropiprant in high-risk patients. $N$ Engl $J$ Med. 2014;371(3):203-212.

24. Cheng SC, Young DO, Huang Y, Delmez JA, Coyne DW. A randomized, double-blind, placebo-controlled trial of niacinamide for reduction of phosphorus in hemodialysis patients. Clin J Am Soc Nephrol. 2008;3(4):1131-1138.

25. Young DO, Cheng SC, Delmez JA, Coyne DW. The effect of oral niacinamide on plasma phosphorus levels in peritoneal dialysis patients. Perit Dial Int. 2009;29(5):562-567.

26. Shahbazian H, Zafar Mohtashami A, Ghorbani A, et al. Oral nicotinamide reduces serum phosphorus, increases HDL, and induces thrombocytopenia in hemodialysis patients: a double-blind randomized clinical trial. Nefrologia. 2011;31(1):58-65.

27. Edalat-Nejad M, Zameni F, Talaiei A. The effect of niacin on serum phosphorus levels in dialysis patients. Indian J Nephrol. 2012;22(3): 174-178.

28. Ahmadi F, Shamekhi F, Lessan-Pezeshki M, Khatami MR. Comparison of efficacy of the phosphate binders nicotinic acid and sevelamer hydrochloride in hemodialysis patients. Saudi J Kidney Dis Transpl. 2012;23(5):934-938.

29. Canner PL, Berge KG, Wenger NK, et al. Fifteen year mortality in Coronary Drug Project patients: long-term benefit with niacin. $J \mathrm{Am}$ Coll Cardiol. 1986;8(6):1245-1255.

30. Clofibrate and niacin in coronary heart disease. JAMA. 1975;231(4): 360-381. 
31. Rubins HB, Robins SJ, Collins D, et al. Gemfibrozil for the secondary prevention of coronary heart disease in men with low levels of high-density lipoprotein cholesterol. Veterans Affairs High-Density Lipoprotein Cholesterol Intervention Trial Study Group. NEngl J Med. 1999;341(6):410-418.

32. Kamanna VS, Ganji SH, Kashyap ML. The mechanism and mitigation of niacin-induced flushing. Int J Clin Pract. 2009;63(9):1369-1377.
33. Dalton TA, Berry RS. Hepatotoxicity associated with sustained-release niacin. Am J Med. 1992;93(1):102-104.

34. Rennick A, Kalakeche R, Seel L, Shepler B. Nicotinic acid and nicotinamide: a review of their use for hyperphosphatemia in dialysis patients. Pharmacotherapy. 2013;33(6):683-690.

\section{Publish your work in this journal}

Therapeutics and Clinical Risk Management is an international, peerreviewed journal of clinical therapeutics and risk management, focusing on concise rapid reporting of clinical studies in all therapeutic areas, outcomes, safety, and programs for the effective, safe, and sustained use of medicines. This journal is indexed on PubMed Central, CAS,
EMBase, Scopus and the Elsevier Bibliographic databases. The manuscript management system is completely online and includes a very quick and fair peer-review system, which is all easy to use. Visit http://www.dovepress.com/testimonials.php to read real quotes from published authors.

Submit your manuscript here: http://www.dovepress.com/therapeutics-and-clinical-risk-management-journal 